\title{
The effect of metoclopramide on gastroduodenal and gallbladder contractions
}

\author{
A. G. JOHNSON \\ From the Department of Surgery, Charing Cross Hospital Medical School, London
}

SUMMARY The effect of metoclopramide on gastroduodenal and gallbladder contractions in the dog has been studied. It increased the strength of antral contractions and produced stronger, more regular, duodenal contractions; these tended to follow those of the antrum, providing evidence of the dominance of antral contraction rate over that of the duodenum. In the absence of spontaneous antral activity, there was little effect on either stomach or duodenum and this was not related to the type of anaesthetic used. There was no effect on the gallbladder when it was relaxed or submaximally stimulated with cholecystokinin/pancreozymin. Further evidence has been obtained that metoclopramide acts by enhancing the local effect of acetylcholine on gastric smooth muscle. These findings provide a satisfactory mechanism for most of the observed clinical effects.

Metoclopramide is being increasingly used for the treatment of nonspecific dyspepsia (Trafford, Fisher, Marshall, and Douthwaite, 1967) and is under trial in the treatment of gastric ulcer. It was first used in France in 1964 and introduced into Britain under the name of Maxolon as an anti-emetic. It is chemically unrelated to any other compound in therapeutic use and has both a central action on the vomiting centre and a peripheral effect on gastric contractions.

James and Hume (1968) and Kreel (1970) have shown radiologically that metoclopramide increases the rate of gastric emptying and accelerates the transit of barium through the small intestine. Fluoroscopic observations suggested that the rapid emptying was due to increased contractile activity in the stomach accompanied by dilatation of the pylorus and duodenum. Jacoby and Brodie (1967) found that it produced a marked acceleration in gastric emptying associated with an increased contractile activity in both anaesthetized and unanaesthetized dogs. The stimulating action appeared to be different from that produced by cholinergic agents in that only gastric contractions were stimulated whereas methacholine stimulated all areas of the gastrointestinal tract simultaneously. Metoclopramide did not stimulate gastric secretion. Connell and George (1969) made similar observations on gastric emptying and secretion in man. Eisner(1968) found that, in vitro, gastric and colonic smooth muscle

Received for publication 6 October 1970. strips responded to metoclopramide only in the presence of acetylcholine.

This paper reports the effect of metoclopramide on gastroduodenal and gallbladder contractions in the anaesthetized dog.

\section{Definition of Terms}

The term 'contraction' refers to an increase in intraluminal pressure and 'rate' refers to the number of contractions in a given period of time. 'Rhythm', on the other hand, means the distribution or spacing of contractions over a period of time, so that a rhythm may be regular or irregular. 'Activity' merely refers to the presence of contractions without any implication about their strength, rate or rhythm. The terms 'motility' and 'motility index' have been avoided because of their ambiguity.

\section{Methods and Techniques}

Mongrel dogs, of both sexes, weighing between 10 and $27 \mathrm{~kg}$ were anaesthetized with sodium pentobarbitone ( $27 \mathrm{mg} / \mathrm{kg}$ intravenously). As there is some evidence that sodium pentobarbitone depresses gastrointestinal activity, two experiments were performed under $a$-glucochloralose (Merck; $80 \mathrm{mg}$ / $\mathrm{kg}$ intravenously), which is a light, non-barbiturate anaesthetic. No atropine or other premedication was given and the animals were intubated to assure an adequate airway. 
Open-tipped, saline-filled polythene tubes were introduced into the distal antrum and duodenal bulb so that no tube was lying across the pylorus. Further tubes were introduced into the stomach and duodenum for aspiration, the stomach being emptied before recordings started. The common bile duct was ligated and canalized so that bile was diverted from the duodenum and a recording tube introduced into the gallbladder via the cystic duct. All three recording tubes were connected to Statham P23 Db pressure transducers recording onto an SE ultra-violet 3006 recorder with a paper speed of $50 \mathrm{~mm} /$ minute.

The standard dose of metoclopramide used was $2 \mathrm{mg} / \mathrm{kg}$ (Jacoby and Brodie, 1967) and the activity of the preparation was checked at the end of each experiment by the administration of pancreozymin (Boots) which stimulates all three organs in the anaesthetized animal (Denton and Gershbein, 1967).

\section{Analysis of Recordings}

The antral tracings were analysed as the average strength of contraction over the number of contractions in the five-minute periods before and after injection of metoclopramide. The duodenal contractions, on the other hand, were divided into five groups by their strength in relation to the maximum contraction recorded during the 10-minute period under study, as follows: grade I between 0 and $19 \%$ of the maximum contraction; grade II between 20 and $39 \%$; grade III between 40 and $59 \%$; grade IV between 60 and $79 \%$; and grade $V$ between 80 and $100 \%$ of the maximum contraction.

A scoring device to favour the stronger contractions (Jacoby and Brodie, 1967) was not used but equal weight given to all levels of contraction as recommended by Vantrappen, Hellemans, and Vandenbroucke (1965). Contractions below $20 \%$ of the maximum contraction (grade I) were ignored because of the difficulty in differentiating them from interference.

\section{Results}

THE EFFECT OF METOCLOPRAMIDE ON ANTRAL CONTRACTIONS

An intravenous injection of metoclopramide produced an immediate increase in the strength of antral contractions without affecting the rate (Fig. 1), and this increase occurred in all animals where spontaneous antral contractions were present. Table I shows the results of 12 tests on eight dogs; using paired $t$ tests the difference is highly significant $(t=3.315 ; P<0.01)$.

On nine occasions metoclopramide was injected when there was no spontaneous antral activity and there was no response at any time even with doses of $3 \mathrm{mg} / \mathrm{kg}$ (Fig. 2). The same animals, however, responded to other stimuli such as pancreozymin and carbachol. Similar observations were made in a dog anaesthetized with chloralose so the failure to respond was not due to the pentobarbitone anaesthetic.

\begin{tabular}{|c|c|c|c|c|}
\hline \multirow[t]{3}{*}{ Dog } & \multicolumn{4}{|l|}{ Contractions } \\
\hline & \multicolumn{2}{|c|}{$\begin{array}{l}5 \text { - } 0 \text { Min Before Metoclo- } \\
\text { pramide }\end{array}$} & \multicolumn{2}{|c|}{$\begin{array}{l}\text { 0 - } 5 \text { Min After Metoclo- } \\
\text { pramide }\end{array}$} \\
\hline & Average Strength & Number & Average Strength & Number \\
\hline 2 & 1.5 & 20 & $5 \cdot 5$ & 21 \\
\hline 4 & $1 \cdot 3$ & 20 & $2 \cdot 6$ & 19 \\
\hline $6(1)$ & 0.7 & 25 & 4 & 25 \\
\hline (2) & 1 & 28 & 4 & 27 \\
\hline $8(1)$ & 0.7 & 20 & $2 \cdot 1$ & 22 \\
\hline (2) & 0.8 & $17^{1}$ & 1.4 & $19^{1}$ \\
\hline 11 & 0.8 & 22 & $1 \cdot 6$ & 23 \\
\hline 12 & 1.8 & 27 & $4 \cdot 3$ & 23 \\
\hline 14 (1) & 0.5 & 20 & $1 \cdot 5$ & 22 \\
\hline (2) & 1 & $13^{2}$ & $2 \cdot 5$ & $13^{2}$ \\
\hline $15(1)$ & $3 \cdot 7$ & 24 & 8 & 24 \\
\hline (2) & 16 & 21 & 28 & 20 \\
\hline
\end{tabular}

Table I Contractions of antrum before and after metoclopramide $(2 \mathrm{mg} / \mathrm{kg})$ expressed as the average strength of contraction $(\mathrm{mm} \mathrm{Hg})$ and the number of contractions in a five-minute period

${ }^{1}$ Over a four-minute period.

'Over a three-minute period. 
THE EFFECT OF METOCLOPRAMIDE ON THE FIRST PART OF THE DUODENUM

The effect on the duodenum was twofold. In all 10 tests when spontaneous activity was present, metoclopramide had an effect (Fig. 3a). Of 17 tests performed when spontaneous duodenal activity was absent, in seven there was a response and in 10 there was no effect. Table II summarizes these findings. When the response of the duodenum in the absence of spontaneous activity was further analysed it was found that the duodenum response was determined by the antral activity. Of the seven instances where the duodenum showed a response, antral activity was present in six (Fig. 1) and in the
10 cases where there was no response, antral activity was absent in nine (Fig. 2). This suggested that the antrum exerted some influence over the duodenum.

In those with spontaneous duodenal activity the effect of metoclopramide was to produce proportionately more of the larger grade contractions. Table III gives examples of these changes in three of the animals studied (dogs 4, 14 (1), and 15 (1)). When a $\chi^{2}$ test is done on a comparison between grade 2 contractions and grades 3,4 , and 5 contractions combined, six out of the 10 show a change of statistical significance and one shows a marked change but the basal contractions were too few for statistical analysis.

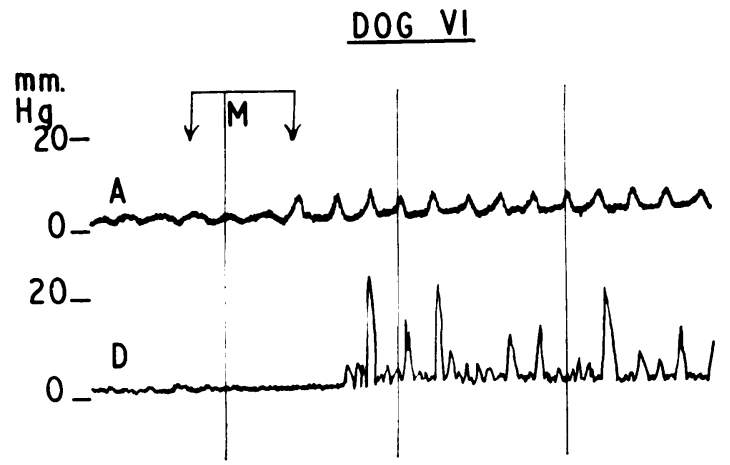

Fig. 1 The effect of metoclopramide $(2 \mathrm{mg} / \mathrm{kg})$ on the antrum (A) and duodenum (D) in the absence of spontaneous duodenal activity. The vertical lines denote one-minute intervals.

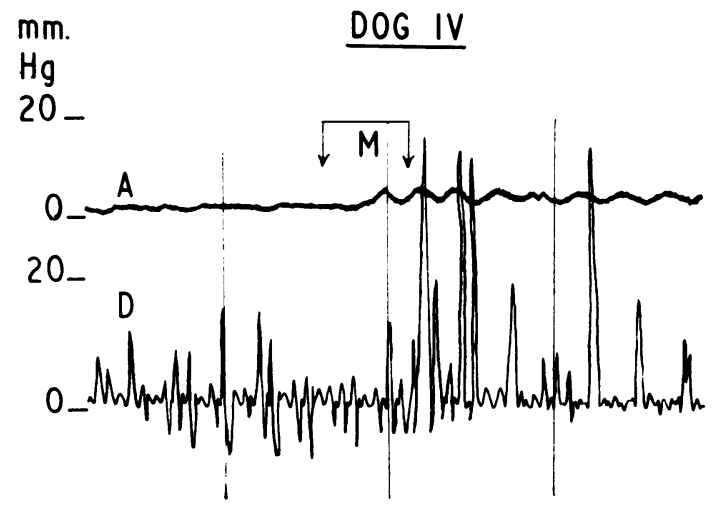

Fig. 3a The effect of metoclopramide $(2 \mathrm{mg} / \mathrm{kg})$ on the antrum (A) and duodenum (D) in the presence of spontaneous duodenal activity. 


\begin{tabular}{lllll}
\hline & \multicolumn{3}{l}{ Grade of Contraction } \\
\cline { 2 - 4 } & 2 & 3 & 4 & 5 \\
\hline
\end{tabular}

$\begin{array}{lrlll}\text { Dog } 4 & & & & \\ \text { Five min before metoclopramide } & 19 & 3 & 1 & 0 \\ \text { Five min after metoclopramide } & 6 & 8 & 2 & 4\end{array}$

$$
\mathbf{P}<0.0001
$$

Dog 14 (1)

Five min before metoclopramide

Five min after metoclopramide $\quad 20$

$$
P<0.05
$$

Dog 15 (1)

$\begin{array}{lllrl}\text { Five min before metoclopramide } & 24 & 20 & 3 & 0 \\ \text { Five min after metoclopramide } & 14 & 18 & 13 & 4\end{array}$

$P<0.05$

Table III Effect of metoclopramide $(2 \mathrm{mg} / \mathrm{kg})$ on the number of duodenal contractions in the presence of spontaneous duodenal activity. Examples from three experiments

In all cases where the total number of duodenal contractions in grades $2,3,4$, and 5 were below 15 in the five-minute period, the number was increased by metoclopramide, whereas in one out of the two with more than 30 contractions this number was reduced and in the other unchanged.

CHANGES IN BASAL PRESSURE AND DURATION OF ACTION OF METOCLOPRAMIDE

In 10 out of 13 tests, there was a slight rise of basal pressure in the antrum usually of 1 to $2 \mathrm{~mm} \mathrm{Hg}$ lasting two to four minutes. In the duodenum there was an equivalent rise in half and an equivalent fall of pressure in half of the tests.
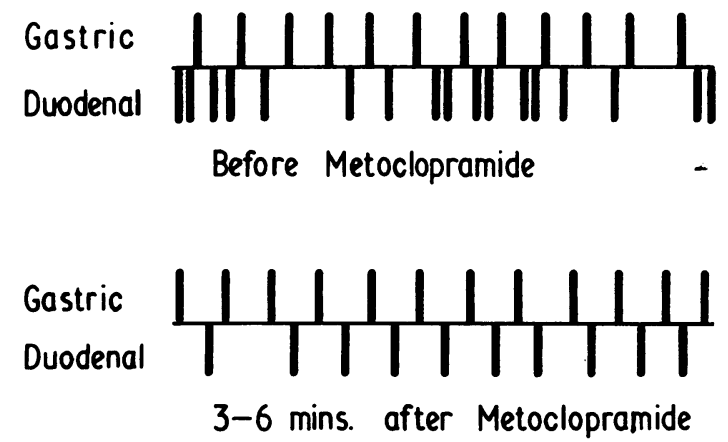

Fig. 4 The relationship between the timing of the antral and duodenal contractions. Each vertical line represents the beginning of a contraction. (From the same recording as Figs. $3 a$ and $3 b$.)
The onset of the response was almost immediate and always within one minute of the end of the intravenous injection. Although it is difficult to determine the exact point when the effect ceased, the average duration of action of a $2 \mathrm{mg} / \mathrm{kg}$ dose was 18 minutes for the antrum, 17 minutes for the duodenum with previous spontaneous activity, and 13 minutes for the duodenum without spontaneous activity.

THE INFLUENCE OF ANTRAL CONTRACTIONS ON THE DUODENUM

The finding that the duodenal response was influenced by the antral response (Table II) led to further analysis of the timing of the duodenal contractions in relation to those of the antrum. Figure $3 \mathrm{~b}$ shows large duodenal contractions occurring in phase with those of the antrum and when the time of the beginning of each gastric and duodenal contraction is recorded it will be seen that the effect of metoclopramide is to produce single duodenal contractions following each antral contraction (Fig. 4). When a $\chi^{2}$ test was used on the number of duodenal contractions between each antral contraction, before and after metoclopramide, this tendency was demonstrated in each of the recordings but did not reach statistical significance at the $5 \%$ level. When, however, the tracings after metoclopramide were compared with an isolated 'burst' of spontaneous duodenal activity, a significant difference was found, only one test failing to reach the $5 \%$ level. The same was true for those with no duodenal activity before metoclopramide was given. It can be said, therefore, that metoclopramide increases the dominance of the antral contraction rate and rhythm over that of the duodenum.

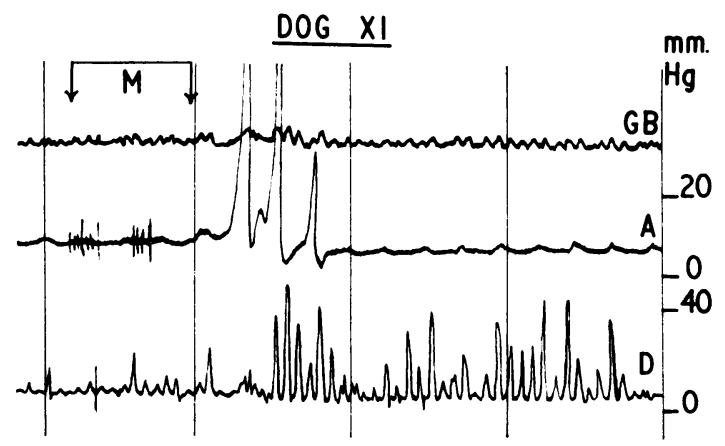

Fig. 5 The effect of metoclopramide $(2 \mathrm{mg} / \mathrm{kg}$ ) on pancreozymin-induced activity of the gallbladder (GB) antrum (A), and duodenum (D). (The irregularities in the gallbladder recordings are respiratory.) 
THE EFFECT OF METOCLOPRAMIDE ON THE GALLBLADDER

Metoclopramide produced no change in gallbladder pressure in any of 12 tests (Fig. 2) and in each case the sensitivity of the preparation was confirmed by a brisk response to pancreozymin.

\section{MODE OF ACTION OF METOCLOPRAMIDE}

Metoclopramide produced a true potentiation of the effect of carbachol $(0.8 \mathrm{mg} / \mathrm{kg})$ on antral contractions. If the antrum, duodenum, and gallbladder were submaximally stimulated by a pancreozymin drip, metoclopramide given during this period potentiated the pancreozymin's effect on the stomach and duodenum (nine tests) but not on the gallbladder (eight tests) (Fig. 5). In four previous tests with metoclopramide alone, in the same animals, there had been no response (Fig. 2).

It was of particular interest, therefore, to find that the effect of pancreozymin on the antrum and duodenum was abolished by atropine whereas the effect on the gallbladder was unaffected. This shows that the antral and duodenal but not the gallbladder effect is mediated through acetylcholine and provides further indirect evidence that metoclopramide acts by enhancing the local effect of acetylcholine (Eisner, 1968).

\section{Discussion}

The basic antral contraction rate in the dog is $5 / \mathrm{min}$ and the basic duodenal rate $17-18 /$ minute. The duodenal bulb, however, has an irregular, basic rhythm that may in some circumstances be influenced by the rate and rhythm of the antrum. In one series of cinematographic observations in dogs, $85 \%$ of all duodenal contractions seen while strong (type II) waves were passing over the antrum occurred during terminal antral contraction. When weak (type I) waves passed over the stomach, duodenal contractions were randomly distributed throughout the antral cycle (Davenport, 1966). This agrees with the findings reported here that increasing the strength of antral contractions increases the dominance of the antral rate over that of the duodenal bulb. Bennett and Whitney (1966) found that muscle from the first part of the duodenal cap had no intrinsic cholinergic activity and showed little response to acetylcholine in vitro, whereas muscle from the antrum and second part of duodenum had intrinsic activity and showed a moderate response to acetylcholine. Metoclopramide, therefore, because of its mode of action, would be expected to have a greater effect on the antrum than on the duodenal bulb, which is what has been found. Bortoff and Davis (1969) have recently pointed out the importance of myogenic transmission of antral electrical slow wave activity across the pylorus as a possible coordinating factor in gastric emptying; they have shown how the antral rate can be superimposed on that of the duodenum, particularly following augmentation of the antral slow wave by vagal stimulation. Metoclopramide may well produce a similar effect.

The findings reported here provide a mechanism for some of the clinically observed effects of metoclopramide. Gastric emptying will be speeded by an increase in the strength of antral contractions (Hunt, 1963). The use of open tipped catheters instead of balloons ensures that the contractions being recorded are those that increase intraluminal pressure and so affect the movement of gastric contents. The coordination of antral and duodenal contractions will further speed gastric emptying and tend to prevent reflux of duodenal contents back through the pylorus, as the duodenal bulb will only contract during a terminal antral contraction. A relaxation of the duodenal bulb as described by radiologists has not been observed, if by relaxation is meant the absence of contractions and a reduced baseline pressure, but contractions of the duodenal bulb in phase with those of the antrum, accompanied by a more rapid gastric emptying, would result in good filling of the duodenal cap with barium.

In practice, therefore, metoclopramide should be useful in hypotonic gastric states and conditions associated with delayed gastric emptying and pyloric reflux but it will be antagonized by anticholinergic drugs. It will enhance the effect on antral smooth muscle of locally released acetylcholine whether this is initiated by intrinsic activity, extrinsic nervous stimulation, or gastrointestinal hormones. It will be effective after vagotomy as intrinsic activity is not completely abolished, but in the rare cases of true gastric atony there will probably be no effect.

I am grateful to Professor A. J. Harding Rains for his help in the preparation of this paper, which is based on a communication to the Surgical Research Society, and to Mr C. J. C. Kirk and Miss C. March for invaluable technical assistance. Dr O. P. W. Robinson of Beecham's Research Laboratories kindly provided the metoclopramide, and I am grateful to Mr J. J. Grimshaw for his expert statistical advice.

This work constitutes part of the requirements for the MChir Degree of Cambridge University and was supported by a Charing Cross Hospital Governors' research fellowship.

\footnotetext{
References

Bennett, A., and Whitney, B. (1966). A pharmacological study of the motility of the human gastro-intestinal tract. Gut, 7, 307-316.
} 
Bortoff, A., and Davis, R. S. (1969). Myogenic transmission of antral slow waves across the gastro-duodenal junction: A possible co-ordinating mechanism in gastric emptying. (Abstr.) (Paper read to the 2nd International Symposium on Gastro-intestinal Motility.) R.C. Riunioni Rom. Gastro-ent. I, N2 Suppl., 136.

Connell, A. M., and George, J. D. (1969). Effect of metoclopramide on gastric function in man. Gut, 10, 678-680.

Davenport, H. W. (1966). Physiology of the Digestive Tract, 2nd ed. Year Book Medical Publishers, Chicago.

Denton, R. W., and Gershbein, L. L. (1967). In vivo contractility of smooth muscle by cholecystokinin concentrates. Arch. int. Pharmacodyn., 166, 473-485.

Eisner, M. (1968). Gastrointestinal effects of metoclopramide in man. In vitro experiments with human smooth muscle preparations. Brit. med. J., 4, 679-680.
Hunt, J. N. (1963). The duodenal regulation of gastric emptying. Gastroenterology, 45, 149-156.

Jacoby, H. I., and Brodie, D. A. (1967). Gastrointestinal actions of metoclopramide. Gastroenterology, 52, 676-684.

James, W. B., and Hume, R. (1968). Action of metoclopramide on gastric emptying and small bowel transit time. Gut, 9, 203-205.

Kreel, L. (1970). The use of oral metoclopramide in the barium meal and follow-through examinations. Brit. J. Radiol., 43, 31-35.

Trafford, J. A. P., Fisher, A. M. H., Marshall, S., and Douthwaite, A. H. (1967). Metoclopramide ('Maxolon') - A new antiemetic. Brit. J. clin Prac., 21, 457-460.

Vantrappen, G., Hellemans, J., and Vandenbroucke, J. (1965). A method for the analysis of intestinal motility records. Amer. J. dig. Dis., 10, 449-454. 